\title{
SUBSÍDIOS AO PLANEJAMENTO TERRITORIAL DE CAMPINAS: A APLICAÇÃO DA ABORDAGEM DE TIPOS DE TERRENO
}

\author{
Sueli YOSHINAGA \\ Amélia João FERNANDES \\ Sônia A. Abissi NOGUEIRA \\ Seiju HASSUDA \\ Antônio Gonçalves PIRES NETO
}

\section{RESUMO}

Aprresenta-se aqui o resultado da análise integrada de um trabalho multidiciplinar que engloba estudos geológicos, geomorfológicos, hidrogeológicos e de recursos minerais (escala 1:50.000), realizados no Município de Campinas pelo Instituto Geológico-SMA, onde se utilizou a abordagem de Tipos de Terreno. O principal produto desta análise foi a delimitação de seis "Tipos de Terreno" em um mapa-síntese, onde cada tipo de ocupação (urbana, industrial e agropecuária) foi classificado como favorável, apropriada, restrita ou imprópria em função das características avaliadas.

\section{ABSTRACT}

This paper presents the result of a multidisciplinary research encompassing geological, geomorphological, mineral resources and hydrogeological studies (on a 1:50.000 scale), carried out in the Campinas Municipality. The "terrain types" approach was used. The main product was the delimitation of six "terrain types" in a synthesis map where each kind of occupation (urban, industrial and rural) was classified as favorable, suitable, restricted or unsuitable, regarding the evaluated characteristics.

\section{INTRODUÇÃO}

O presente trabalho apresenta os resultados do projeto "Subsídios do meio físico-geológico no Planejamento do Município de Campinas" (INSTITUTO GEOLÓGICO, 1993), desenvolvido dentro do Programa "Cartas geológicas e geotécnicas para o planejamentos ambiental entre Sorocaba e Campinas.

O município de Campinas ocupa uma área de $790 \mathrm{~km}^{2}$ e dista cerca de $100 \mathrm{~km}$ da cidade de São Paulo. Contém hoje uma população de cerca de um milhão de habitantes, situando-se na área de conurbação da bacia do rio Piracicaba. O intenso e acelerado processo de metropolização, resultante do avanço das indústrias para o interior do Estado, é responsável pela riqueza da região e conseqüentemente pela degradação ambiental decorrente do processo de urbanização sem planejamento efetivo.

A análise conjunta dos estudos geológicos (FERNANDES et al., 1993), geomorfológicos (PIRES NETO et al., 1993), hidrogeológicos (HASSUDA et al., 1993) e de recursos mine- rais (NOGUEIRA et al., 1993), em escala de 1:50.000, teve como objetivo orientar o usuário, seja ele planejador, administrador ou da iniciativa privada, para o uso mais conveniente de cada porção do município, seja urbano, industrial ou agropecuário.

\section{ASPECTOS METODOLÓGICOS}

Para a análise integrada dos dados obtidos foi utilizado o conceito de Tipo de Terrenos, conforme descrito por PIRES NETO \& LEPSCH (1992) e YOSHINAGA et al., (1993). A elaboração de um mapa-síntese, em escala 1:50.000, foi feita com base no relevo, onde os Tipos de Terreno são caracterizados pela presença de formas, tipos e padrão de distribuição dos solos e processos superficiais uniformes.

No mapa foram ainda delimitadas áreas que apresentam potencialidades destacadas (bens minerais ou água subterrânea) ou fragilidades acentuadas (intensos processos erosivos, enchentes periódicas e presença de matacões). 
Estes fatores, muitos vinculados diretamente à natureza e estruturação do substrato rochoso, devem ser avaliados em conjunto com as características dos tipos de terreno para se evitar que a sua ocupação inviabilize o aproveitamento dos principais recursos naturais ou que, ao contrário, degrade o meio e/ou onere o poder público.

Os tipos de terrenos, avaliados quanto à adequabilidade aos usos urbano, industrial e agropecuário, foram classificados como: favoráveis, apropriados, restritos ou impróprios. A cada uma destas classificações correspondem cuidados simples específicos ou severos. Esta avaliação consta em uma tabela que acompanha o mapa-síntese.

As recomendações que vêm em tabelas dentro do texto explicativo, foram subdivididas em recomendações gerais e específicas, que visam orientar o usuário e o poder público no seu papel fiscalizador e ordenador das atividades humanas em seu território, de modo a desenvolver uma intervenção no meio físico, mais racional, econômica e direcionada para a conservação dos recursos naturais.

As recomendações gerais compreendem as noções e orientações básicas sobre as drenagens naturais, o solo, a declividade das vertentes e as rochas, que são os componentes do meio físico que mais diretamente condicionam e sofrem os impactos da atividade humana. As recomendações específicas compreendem as regras básicas para a implantação das atividades humanas e a mitigação dos impactos associados.

\section{RESULTADOS OBTIDOS}

O Município de Campinas subdivide-se em dois grandes compartimentos geomorfológicos: o Planalto Atlântico, a leste, a Depressão Periférica, a oeste, sendo notada ainda uma área de transição entre eles.

A disposição do relevo vincula-se à ocorrência de rochas gnáissicas do Complexo Itapira, graníticas das suítes Jaguariúna e Morungaba e miloníticas, a leste; e de arenitos, ritmitos e lamitos do Subgrupo Itararé, junto com diabásios da Formação Serra Geral, a oeste. As principais estruturas geológicas ocorrentes na região são as zonas de cisalhamento Valinhos e Campinas (FERNANDES et al., 1993), que muitas vezes servem de limites para as unidades geomorfológicas.

Dentro do domínio do primeiro compartimento situam-se dois tipos de terrenos: os Amorreados de inclinação moderada a forte e os Amorreados ondulados a inclinados (Fig. 1).
Nestes terrenos o solo é podzólico vermelho-amarelado, com textura grossa e de cascalhos nos horizontes superiores. Apresentam alta susceptibilidade à erosão devido ao tipo de solo e às altas declividades (12 a $30 \%$ nos Amorreados de inclinação moderada a forte e 9 a $21 \%$ nos Amorreados ondulados a inclinados). As ocupações urbana e a agropecuária foram consideradas apropriadas e a industrial, imprópria.

Nestas duas unidades e, de um modo geral, no Planalto Atlântico, a ação catalisadora dos processos morfodinâmicos é decorrente de uma ocupação histórica, que promoveu o desmatamento e a remoção da cobertura superficial do solo, favorecendo a aceleração dos processos erosivos, naturais, em áreas de dissecação natural do relevo (vertentes e cabeceiras de drenagem), onde atualmente voçorocas e ravinamentos são freqüentes.

Nos distritos de Souzas e Joaquim Egídio, a expansão urbana e a exploração dos granitos são as causas principais da aceleração da dinâmica superficial, como ocorre no loteamento Morada das Nascentes, Colinas do Ermitage e as áreas de mineração de granitos nas proximidades do Observatório de Capricórnio. A exploração não racional de material de empréstimo e a existência de áreas abandonadas também provocam a instalação de processos erosivos e assoreamento de vales.

A presença de matacões em superfície e enterrados, ocorrendo principalmente na área da suíte granítica Morungaba, representa uma limitação ao uso deste terreno para a qual são feitas recomendações específicas (Fig. 2)

A potencialidade de recursos minerais nestes terrenos está associada à ocorrência de granitos porfiríticos equigranulares, da Suíte Granítica Morungaba, onde a presença de matacões fornece material para rocha ornamental, de talhe e cantaria.

Nestes terrenos a área de maior potencial para produção de água subterrânea está associada a gnaisses do Complexo Itapira e a granitos da Suíte Jaguariúna muito fraturados, que ocorrem entre as zonas de cisalhamento de Valinhos e Campinas, que se estende ainda para os Terrenos Colinosos ondulados a inclinados e parte dos Terrenos Colinosos suavemente ondulados.

Os Terrenos Amorreados caracterizam a área de recarga de aqüíferos locais, que devido ao baixo grau de ocupação faz de muitas nascentes que afloram na área e das cacimbas os principais tipos de captações de água subterrânea. $\mathrm{O}$ aquíf́re cristalino neste terreno pode ser 
utilizado para abastecimento público de pequenos núcleos urbanos e para a indústria em geral.

Os Terrenos Colinosos ondulados a inclinados, onde ocorrem gnaisses do Complexo Itapira, representam a transição entre a Depressão Periférica e o Planalto Atlântico. O solo é podzólico vermelho-amarelado, com textura areno-argilosa a arenosa nas porções superficiais e argilosa a siltosa nas inferiores.

Estes terrenos foram classificados como apropriados aos diversos tipos de ocupação. Os processos morfodinâmicos são de baixa intensidade e os solos apresentam erodibilidade moderada; no entanto, também se observam voçorocas ocasionais (Fig. 2) que são decorrentes da remoção da cobertura superficial sem critérios técnicos.

Os Terrenos Colinosos suavemente ondulados e os Colinosos ondulados fazem parte da Depressão Periférica. Diabásios, arenitos, ritmitos e lamitos e, subordinadamente, rochas graníticas e gnáissicas (Complexo Itapira e suíte Jaguariúna) compõem o substrato dos Terrenos Colinosos suavemente ondulados (Fig. 1). Sobre os diabásios ocorre o latossolo roxo de grande espessura, textura argilosa, muito permeável e fértil. O latossolo vermelho-amarelado, que ocorre sobre o Subgrupo Itararé, possui textura média e é muito permeável, sendo ambos de erodibilidade baixa.

Os Terrenos Colinosos ondulados (Fig. 1) apresentam substrato rochoso composto de arenitos, ritmitos e lamitos do Subgrupo Itararé. Predomina o solo podzólico vermelho-amarelado, de textura média, arenoso em superfície e siltoso em profundidade; mas também ocorrem areias quartzosas podzólicas profundas.

Os Terrenos Colinosos ondulados ocorrem ainda dentro do domínio do Planalto Atlântico na forma de alvéolos associados ao rio Atibaia e ao ribeirão das Cabras. Eles são condicionados por soleiras estruturais (falhas de direção NW) que favoreceram a sedimentação e a ampliação das planícies fluviais nestes locais.

A intensidade dos processos erosivos é baixa em toda a Depressão Periférica, sendo ainda menos intensos nos Terrenos Colinosos suavemente ondulados, devido às baixas declividades (variando de 2 a 16\%). A ocorrência de voçorocas e ravinamentos (Fig. 2) é devida à remoção de parte do solo e à concentração do escoamento de água superficial (Jardim do Lago, Jardim Novos Campos Elísios, Distrito Industrial, Parque Vista Alegre e algumas áreas de retirada de material de empréstimo) junto às cabeceiras de drenagem que estão dissecando uma antiga superfície erosiva.
De um modo geral os terrenos da Depressão Periférica são favoráveis à ocupação urbana, industrial e agropecuária, necessitandose de cuidados simples e específicos principalmente para evitar o desencadeamento dos processos erosivos.

Os recursos minerais destes terrenos estão associados a ocorrências de diabásio para brita, cuja potencialidade máxima situa-se em área com cobertura de espessura menor que $20 \mathrm{~m}$, e aos ritmitos e lamitos do Subgrupo Itararé (argila tipo Taguá) que são explorados para cerâmica vermelha.

Os recursos de água subterrânea estão associados ao aqüífero sedimentar Tubarão, em áreas onde afloram ritmitos e lamitos com arenitos em profundidade. A vulnerabilidade natural do Sistema Aqüífero Tubarão é considerada baixa e localmente média, sendo recomendável para a disposição de resíduos e efluentes (domésticos e industriais) as áreas de vulnerabilidade baixa.

Em algumas áreas de ocupação de baixa renda e sem saneamento básico foi detectada a contaminação de poços-cacimba por fossas negras (Jardim Campo Belo, Vila Nilza, Jardim São Judas Tadeu e Satélite Íris), que mostrou a necessidade de estudos para detectar e evitar este tipo de contaminação em todas as áreas de ocupação de baixa renda do município, bem como priorizar a instalação de saneamento básico (água e esgoto) nestes locais.

As Planícies Fluviais são pouco desenvolvidas nos terrenos do Planalto Atlântico, onde as de maior expressão estão associadas às ocorrências locais de soleiras. Na Depressão Periférica compreendem as planícies de inundação (várzeas) e os baixos terraços, estendendose até as cabeceiras das drenagens.

A ocưpação destes terrenos é imprópria principalmente em decorrência da elevada vulnerabilidade natural dos aquíf́eros das planícies de inundação e terrenos onde se tem a possibilidade de contaminação do aqüífero freático por disposição de resíduos domésticos, industriais e por fossas negras e pelo risco de erosão das margens e inundações intensificadas pela diminuição da capacidade de infiltração da bacia devido à pavimentação das áreas intensamente urbanizadas.

Os problemas nestas áreas, intensificados pela operação de lavras de argila e areia de forma não racional, promovem o assoreamento de rios e degradam a planície com a abertura de cavas semi-secas e alagadas, além de comprometer intensamente a mata ciliar. 


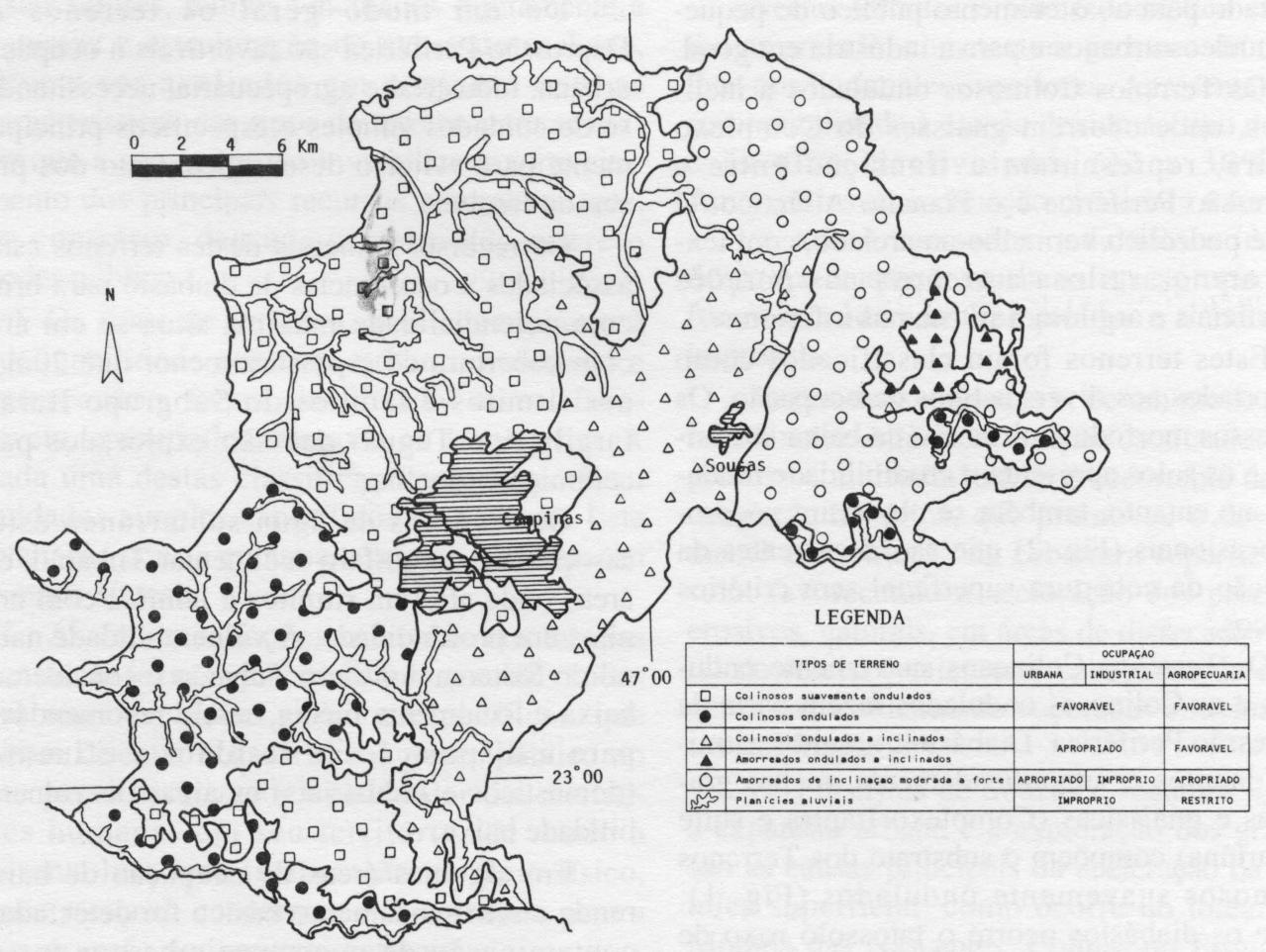

FIGURA 1 - Esboço do Mapa de Tipos de Terreno do Município de Campinas (IG, 1993)

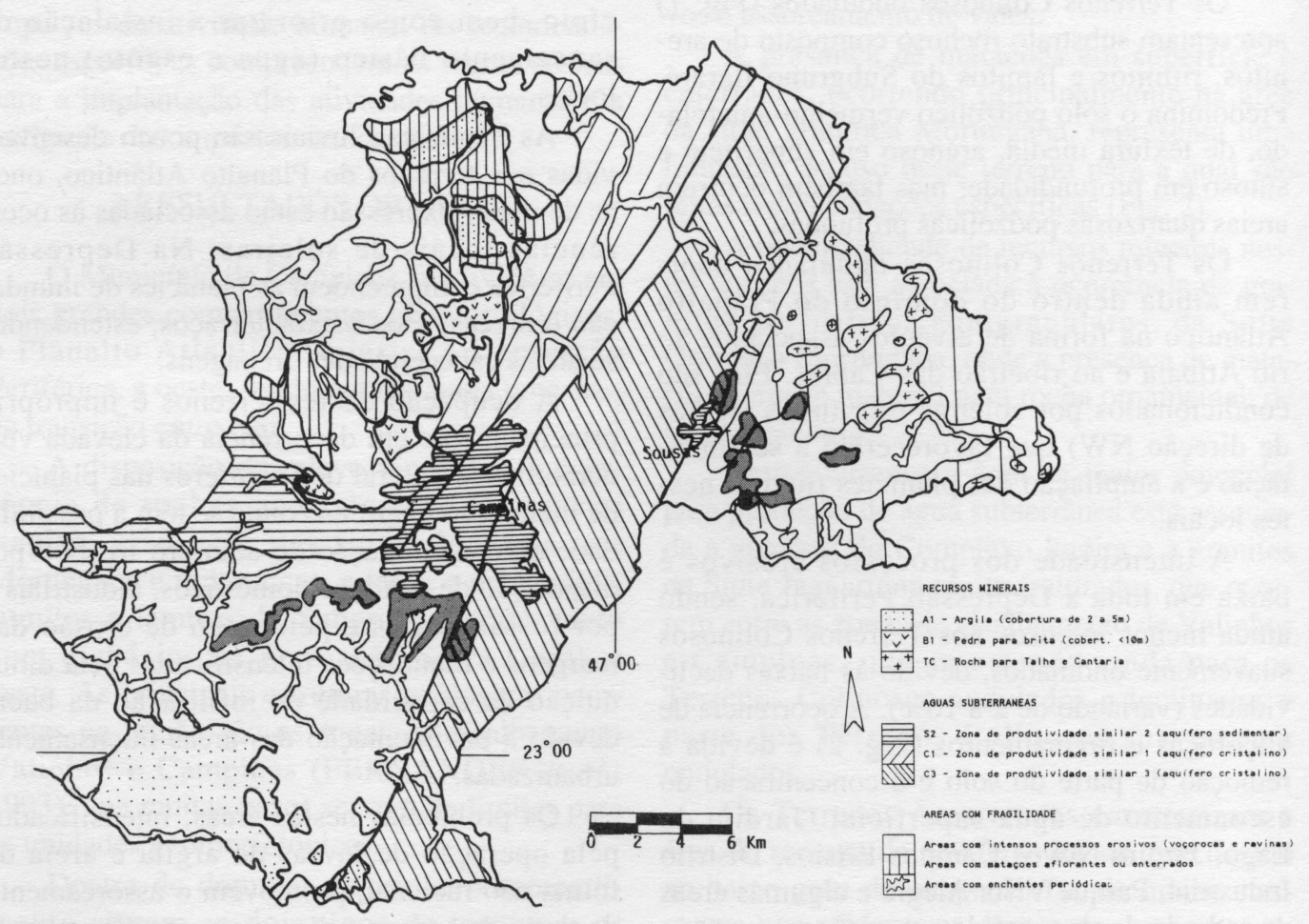

FIGURA 2 - Esboço do Mapa de Tipos de Terreno do Município de Campinas. Potencialidades e Fragilidades (IG, 1993). 


\section{CONSIDERAÇÕES FINAIS}

A metodologia adotada permitiu a elaboração de um mapa-síntese relativamente simples, que procura fornecer informações para a minimização da degradação do meio, bem como a perda de recursos naturais.

Para isto procurou-se indicar o resultado das interações existentes entre o relevo, os solos e a distribuição dos processos morfodinâmicos, representados pelas potencialidades e fragilidades dos terrenos, associados às áreas de maior potencial para a exploração de águas subterrâneas e de recursos minerais, de modo a permitir uma avaliação integrada do meio e a definição do uso mais adequado de cada porção do Município.

\section{REFERÊNCIAS BIBLIOGRÁFICAS}

FERNANDES, A.J.; AZEVEDO SOBRINHO, J.M.; TEIXEIRA, A.L.; BOGGIANI, P.C.; GARDA, G.M. 1993. Geologia do município de Campinas. In: Subsídios do meio físico-geológico ao planejamento do município de Campinas (SP). Instituto Geológico SMASP, v. 2, p. 2-51.

HASSUDA, S.; ODA, G.H.; IRITANI, M.A.; LOPES, M.C.; BERTOLO, R.; HIRATA, R.C.A.; FERREIRA, L.M.R. 1993. Hidrogeologia do Município de Campinas. In: Subsídios do meio físicogeológico ao planejamento do município de Campinas (SP). Instituto Geológico SMASP, v. 2, p. 139-176.

INSTITUTO GEOLÓGICO. 1993. Subsídios do meio físico-geológico ao planejamento do município de Campinas (SP). Programa Cartas geológicas e geotécnicas para o planejamento ambiental na região entre Sorocaba e Campinas. São Paulo. 3v.

NOGUEIRA, S.M.A.; LEMOS, A.C.P.N.; SOARES, P.V. 1993. Recursos Minerais do município de Campinas. In: Subsídios do meio físico-geológico ao planejamen- to do município de Campinas (SP). Instituto Geológico - SMASP, v. 2, p. 82-138.

PIRES NETO, A.G. \& LEPSCH, I.F. 1992. A análise geomorfológica como base para os estudos das potencialidades do meio físico e sua aplicação no macrozoneamento e no planejamento territorial. Município de Nova Friburgo (RJ). In: CONGRESSO BRASILEIRO DE GEOLOGIA, 37, São Paulo, 1992. Anais. São Paulo, SBG, v. 2, p. 56-57.

PIRES NETO, A.G.; CASTRO, S.A.P. de; MENDES, E.A.A.; GOULART, A.C. de O.; TOMINAGA, L.K. 1993. Geomorfologia do município de Campinas. In: Subsídios do meio físicogeológico ao planejamento do município de Campinas (SP). Instituto Geológico SMASP, v. 2, p. 52-81.

YOSHINAGA, S.; PIRES NETO, A.G.; FERNANDES, A.J.; CASTRO, S.A.P.; GOULART, A.C.O. 1993. Relatório de Integração. In: Subsídios do meio físicogeológico ao planejamento do município de Campinas (SP). Instituto Geológico SMASP, v.1, 74 p.

Endereço dos autores:

Sueli Yoshinaga, Amélia João Fernandes, Sônia A. Abissi Nogueira, Seiju Hassuda e Antônio Gonçalves Pires Neto - Instituo Geológico Secretaria do Meio Ambiente do Estado de São Paulo - Av. Miguel Estéfano, 3.900 - Água Funda - 04301-903 - São Paulo - SP - Brasil. 